\title{
Immunohistochemical staining of normal, hyperplastic, and neoplastic adrenal cortex with a monoclonal antibody against $\alpha$ inhibin
}

\author{
W G McCluggage, J Burton, P Maxwell, J M Sloan
}

Department of Pathology, Royal Group of Hospitals Trust, Grosvenor Road, Belfast BT12 6BL, UK

W G McCluggage

J Burton

P Maxwell

The Queen's

University of Belfast, Grosvenor Road, Belfast BT12 6BL, UK

J M Sloan

Corrrespondence to: Dr McCluggage.

Accepted for publication 9 December 1997

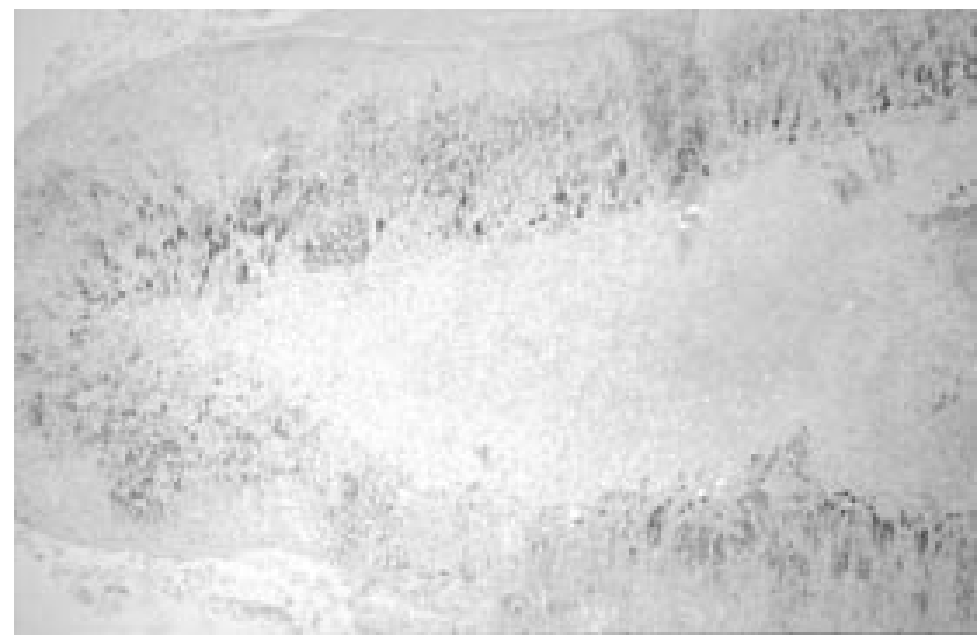

Figure 1 Immunohistochemical staining of normal adrenal gland with anti-a inhibin monoclonal antibody. Positivity is largely confined to the inner layers of the cortex, with no staining of the medulla.

\begin{abstract}
Aims-To investigate the immunohistochemical staining of normal, hyperplastic, and neoplastic adrenal cortex with a monoclonal antibody against $\alpha$ inhibin. Also, to determine whether immunostaining with this antibody is useful in differentiating between adrenal cortical neoplasms and other tumours involving the adrenal gland that might mimic them.

Methods-Normal adrenal tissue $(n=20)$ and specimens from cases of adrenal hyperplasia $(n=13)$, adrenal cortical adenoma $(\mathbf{n}=15)$, adrenal cortical carcinoma $(n=4)$, phaeochromocytoma $(n=8)$, and adrenal metastatic tumour $(n=7)$ were stained with a monoclonal antibody against the $\alpha$ subunit of human inhibin.

Results-Positive staining with the anti-a inhibin monoclonal antibody was seen in all normal adrenal glands. Immunoreactivity was largely confined to the inner cell layers of the adrenal cortex, with no staining of the adrenal medulla. All hyperplastic adrenal glands and adrenal cortical adenomas and carcinomas were also immunoreactive. The other tumours studied were negative.

Conclusions-There is consistent immunoreactivity with the anti- $\alpha$ inhibin monoclonal antibody in normal adrenal cortex and in hyperplastic and neoplastic adrenal cortical lesions. In the normal adrenal cortex, positive staining is mainly confined to the zona reticularis. Other neoplasms involving the adrenal gland are
\end{abstract}

\section{Materials and methods}

Specimens included in the study were retrieved from the files of the department of pathology, Royal Group of Hospitals Trust, Belfast. Most of the specimens were surgical biopsy material, although eight normal adrenal glands and two adrenal cortical adenomas were derived from postmortem material. Table 1 shows the cases studied. The 13 cases of adrenal cortical hyperplasia comprised seven associated with Cushing's syndrome and six with Conn's syndrome. The 15 adenomas comprised 10 associated with Cushing's syndrome, three with Conn's syndrome, and two that were clinically non-functional. All adrenal cortical carcinomas were clinically non-functional. In these four cases, a diagnosis of malignancy was based on a 


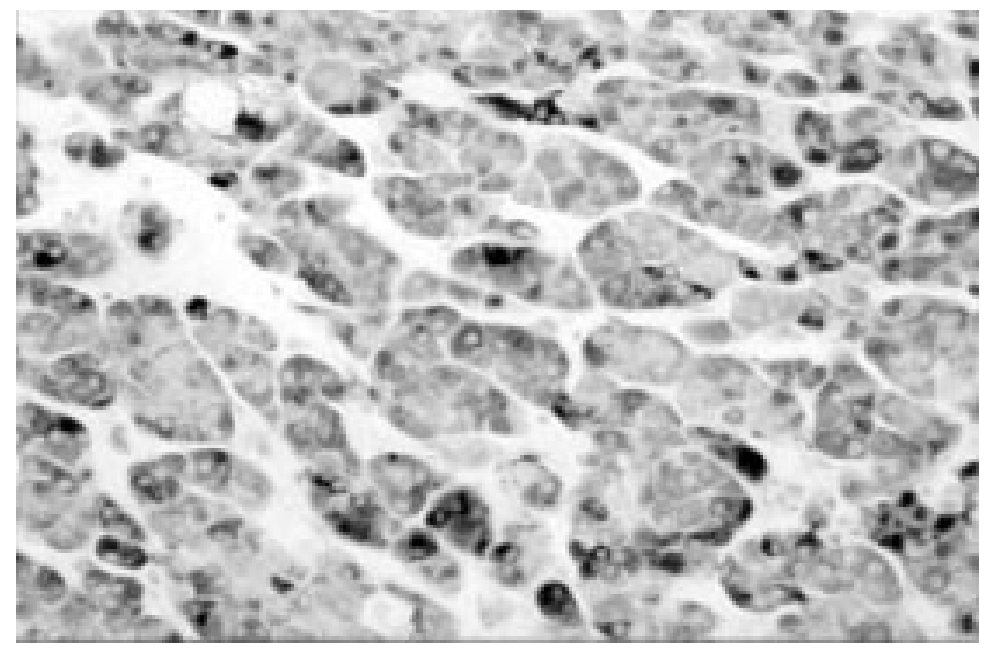

Figure 2 Immunohistochemical staining of adrenal cortical adenoma with anti-a inhibin monoclonal antibody.

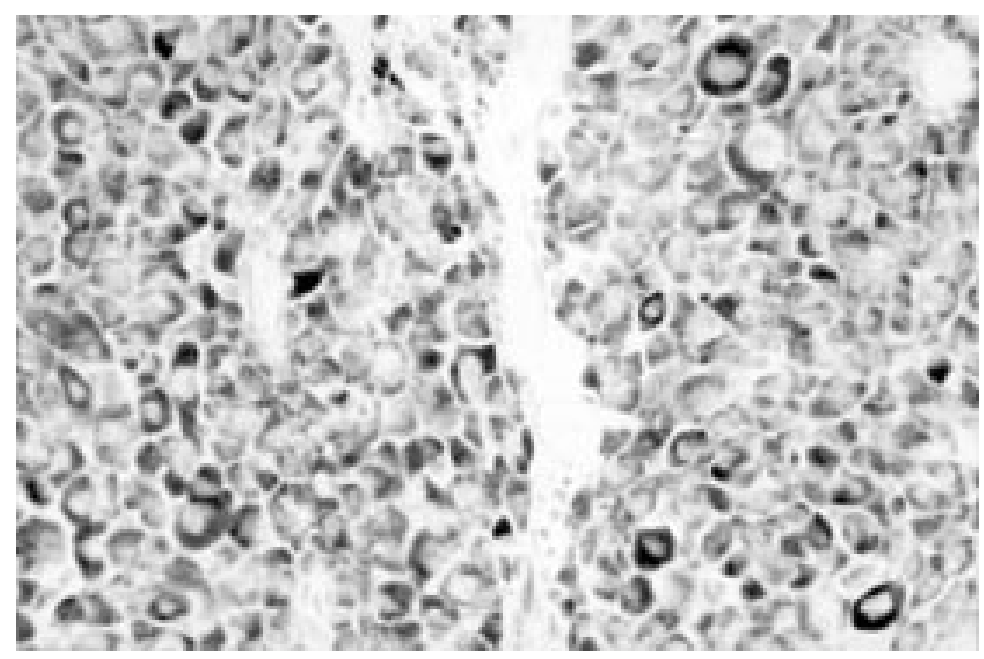

Figure 3 Immunohistochemical staining of adrenal cortical carcinoma with anti-a inhibin monoclonal antibody.

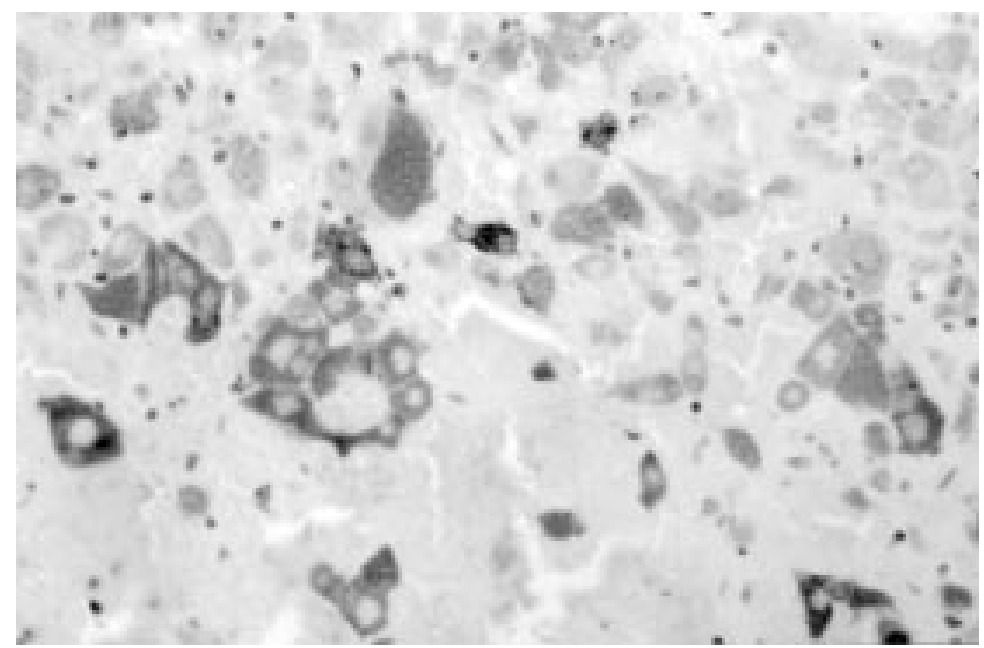

Figure 4 Immunohistochemical staining of adrenal cortical carcinoma containing bizarre cells with anti-a inhibin monoclonal antibody.

combination of clinical and pathological parameters including tumour size, tumour weight, the presence of necrosis, the presence of vascular invasion, nuclear pleomorphism, and mitotic activity. The primary tumours in the cases of adrenal metastases were lung carcinoma
Table 1 Cases included in study

\begin{tabular}{lc}
\hline & Number of cases \\
\hline Normal adrenal & 20 \\
Adrenal cortical hyperplasia & 13 \\
Adrenal cortical adenoma & 15 \\
Adrenal cortical carcinoma & 4 \\
Phaeochromocytoma & 8 \\
Adrenal metastases & 7
\end{tabular}

$(\mathrm{n}=4)$, and single cases of breast carcinoma, renal cell carcinoma, and pleural mesothelioma. All specimens had been fixed in formalin, routinely processed in paraffin wax, and stained with haematoxylin and eosin.

IMMUNOHISTOCHEMICAL STAINING

Sections from paraffin wax embedded blocks were cut on to aminopropyltriethoxysilane treated slides (Sigma, Poole, Dorset, UK) and dried overnight at $37^{\circ} \mathrm{C}$. Endogenous peroxidase activity was blocked in 3\% alcoholic hydrogen peroxide for 10 minutes. Sections were pretreated in an $850 \mathrm{~W}$ domestic microwave oven in citrate buffer $\mathrm{pH} 6.0$ for 20 minutes and allowed to cool for 20 minutes. Sections were incubated for 30 minutes with a mouse monoclonal antibody to human inhibin $32 \mathrm{kDa} \alpha$ subunit ( $1 / 50$ dilution; Serotec, Oxford, UK). Localisation was performed using biotinylated antimouse immunoglobulin (1/200 dilution, Dako, Copenhagen, Denmark) and peroxidase streptavidin biotin complex (Dako). Diaminobenzidine (Dako) was used as the chromagen. Sections were counterstained using Harris's haematoxylin. Negative controls, where the primary antiserum was omitted and replaced with mouse immunoglobulin (Dako), were performed in all cases. Positive controls were also run; these comprised ovaries containing follicular cysts or corpora lutea.

\section{Results}

There was positive staining with the anti- $\alpha$ inhibin monoclonal antibody in all normal adrenal glands. No difference in staining was noted between surgical biopsy and postmortem material. Immunoreactivity was cytoplasmic and granular and was most intense in the inner layers of the adrenal cortex (fig 1), representing the zona reticularis. In some cases, there was weaker staining of the outer layers of the adrenal cortex. There was no staining of the adrenal medulla.

All cases of adrenal cortical hyperplasia and adenoma (fig 2) were also immunoreactive. Positivity ranged from focal to diffuse and was most intense in compact cells with eosinophilic cytoplasm, which resembled the cells of the normal zona reticularis. There was little or no staining of cells with clear cytoplasm. There was no correlation between the pattern of staining and the hormonal profile. All cases of adrenal cortical carcinoma exhibited positive staining. Staining was diffuse in two cases (fig 3) and focal in two. Two cases of adrenal cortical carcinoma were composed of pleomorphic cells and both were positive with the anti- $\alpha$ inhibin monoclonal antibody (fig 4). 
Small numbers of cells were immunoreactive in the case of metastatic mesothelioma. On closer examination, positivity was confined to entrapped adrenal cortical cells. There was no staining of the other tumours studied.

There was strong staining of positive control material in all cases. There was no staining of negative control material.

\section{Discussion}

Ovarian granulosa cells and testicular Sertoli cells are the main sources of circulating inhibin. ${ }^{13}$ However, extragonadal expression also occurs and inhibin $\alpha$ subunits (which are needed for inhibin synthesis) have been detected in the placenta, pituitary gland, adrenal gland, and liver. ${ }^{9-12}$ There is evidence that the adrenals may contribute to circulating inhibin levels. It has been demonstrated that adrenal veins have a higher concentration of inhibin-like immunoreactivity than the vena cava or peripheral veins. ${ }^{14}$

In the present study, we found consistent immunoreactivity in the normal adrenal cortex using an antibody against the $\alpha$ subunit of human inhibin. Immunoreactivity was most intense in the inner cell layers of the normal adrenal cortex, representing the zona reticularis. In some cases, there was weaker staining of the outer layers of the adrenal cortex and it is not possible using immunohistochemical studies alone to ascertain the exact site of inhibin production. This would require the use of alternative methods for the demonstration and localisation of mRNA sequences.

Consistent immunoreactivity with the anti- $\alpha$ inhibin monoclonal antibody was also seen in hyperplastic adrenal glands, in adrenal cortical adenomas, and in the small number of adrenal cortical carcinomas studied. These included both cortisol and aldosterone producing and hormonally non-functional lesions. Immunoreactivity was most intense in compact cells with eosinophilic cytoplasm that histologically resembled those of the zona reticularis. Production of and secretion of inhibin into the circulation has previously been demonstrated in human adrenal tumours, including aldosterone producing, cortisol producing, and clinically non-functional adenomas. ${ }^{14}$

Histological recognition of an adrenal cortical adenoma or carcinoma is generally straightforward, especially when there is a history of hormone production. However, adrenal cortical carcinoma is often hormonally inactive and confusion may arise with other neoplasms, especially phaeochromocytoma or metastatic tumour. The small numbers of adrenal cortical carcinomas in the present study were positive with the anti- $\alpha$ inhibin monoclonal antibody. All other tumours were negative, except for focal positivity in a case of metastatic mesothelioma. In this case it was thought that positivity was confined to residual entrapped adrenal cortical cells. It is possible that immunohistochemical staining with a monoclonal antibody against $\alpha$ inhibin, performed as part of a panel, may prove to be of value in the distinction between adrenal cortical carcinoma and other neoplasms involving the adrenal gland. Antibodies that might be used in such a panel include chromogranin, PGP 9.5, and other neuroendocrine markers, which should be positive in phaeochromocytoma. Anticytokeratin antibodies and antisera against carcinoembryonic antigen may also be utilised depending on the differential diagnosis considered.

1 Arora DS, Cooke IE, Ganesan TS, et al. Immunohistochemical expression of inhibin/activin subunits in epithelial and granulosa cell tumours of the ovary. $f$ Pathol 1997;181:413-18.

2 McLachlan RI, Robertson DM, Healy DL, et al. Cirulating mmunoreactive inhibin levels during the normal menstrual cycle. F Clin Endocrinol Metab 1987: 65:954-961.

3 Lappohn RE, Burger HG, Bouma J, et al. Inhibin as a marker for granulosa cell tumors. $N$ Engl f Med 1989;321: $790-3$.

4 Cooke I, O'Brien M, Charnock FM, et al. Inhibin as a marker for ovarian cancer. Br f Cancer 1995;71:1046-50.

5 McCluggage WG, Maxwell P, Sloan JM. Immunohistochemical staining of ovarian granulosa cell tumors with monoclonal antibody against inhibin. Hum Pathol 1997;28: monoclonal

6 Flemming P, Wellmann A, Maschek H, et al. Monoclonal antibodies against inhibin represent key markers of adult granulosa cell tumors of the ovary even in their metastases. Am F Surg Pathol 1995;19:927-33.

7 Stewart CJR, Jeffers MD, Kennedy A. Diagnostic value of inhibin immunoreactivity in ovarian gonadal stromal tumours and their histological mimics. Histopathology 1997;31:67-74.

8 Rishi M, Howard LN, Bratthauer GL, et al. Use of monoclonal antibody against human inhibin as a marker for sex cord-stromal tumors of the ovary. Am f Surg Pathol 1997;21:583-9.

9 Meunier H, Rivier C, Evans RM, et al. Gonadal and extragonadal expression of inhibin $\alpha, \beta \mathrm{A}$ and $\beta \mathrm{B}$ subunits in various tissues predicts diverse functions. Proc Natl Acad Sci USA 1988;85:247-51.

0 Crawford RJ, Hammond VE, Evans BA, et al. $\alpha$-Inhibin gene expression occurs in the ovine adrenal cortex, and is regulated by adrenocorticotrophin. Mol Endocrinol 1987;1: 699-706.

11 McCluggage WG, Maxwell P, Patterson A, et al. Immunohistochemical staining of hepatocellular carcinoma with monoclonal antibody against inhibin. Histopathology 1997; 30:518-22.

12 McCluggage WG, Ashe P, McBride $\mathrm{H}$, et al. Localisation of the cellular expression of inhibin in trophoblastic tissue. Histopathology. [In press.]

13 Voutilainen R. What is the function of adrenal inhibins? Eur $\mathcal{F}$ Endocrinol 1995;132:290-1.

14 Nishi $Y$, Haji $M$, Takayanagi $R$, et al. In vivo and in vitro evidence for the production of inhibin-like immunoreactivity in human adrenocortical adenomas and normal adrenal glands: relatively high secretion from adenomas manifesting Cushing's syndrome. Eur f Endocrinol 1995;132:292-9. 